\title{
A Study of Preparation and Analysis of a Synthetic Polymer Coagulant
}

\author{
Jeje JO* \\ Department of Civil Engineering, Obafemi Awolowo University, Nigeria
}

*Corresponding author: Jeje JO, Department of Civil Engineering, Obafemi Awolowo University, Ile-Ife, Osun State, Nigeria; Tel: +234- 803-344-7243; E-mail: jemails2000@yahoo.co.uk

Received: 25 Nov, 2019 | Accepted: 03 Jan, 2020 | Published: 09 Jan, 2020

Citation: Jeje JO (2020) A Study of Preparation and Analysis of a Synthetic Polymer Coagulant. Int J Water Wastewater Treat 6(1): dx.doi. org/10.16966/2381-5299.163

Copyright: (c) 2020 Jeje JO. This is an open-access article distributed under the terms of the Creative Commons Attribution License, which permits unrestricted use, distribution, and reproduction in any medium, provided the original author and source are credited.

\begin{abstract}
This study addressed the limitations of using inorganic coagulants in the treatment of surface water by evaluating the efficiency of synthetic polymers as coagulants agents in the chemical purification process. The limitations of inorganic coagulants include; discharge of residual metals into downstream waters, over dependence on $\mathrm{pH}$, high dosage and high sludge production. A synthetic polymer coagulant was prepared by dispersing $1 \mathrm{~g}$ of cassava starch in $100 \mathrm{ml}$ distilled water, making it up to a litre with hot water $\left(80^{\circ} \mathrm{C}-100^{\circ} \mathrm{C}\right)$, adding $1 \mathrm{ml}$ of $1 \mathrm{~N} \mathrm{H} 2 \mathrm{SO} 4$ and electrolyzing by means of a stabilized power supply unit at a current of 0.15 amps using aluminium rods as electrodes. Addition of $1 \mathrm{~g}$ of activated carbon to serve as a coagulant aid (Sample A) resulted in a better turbidity removal than the one without the aid (Sample B). Sample A was found to be almost as effective as alum both at neutral and basic mediums causing better than $80 \%$ turbidity removal at $\mathrm{pH} 7$ and more than $89 \%$ turbidity removal at pH 9 with dosage of $20 \mathrm{ml}(20 \mathrm{~g}$ ) of sample A. Preliminary cost analysis showed that sample A was more economical than alum.
\end{abstract}

Keywords: Synthetic polymer; Starch; Activated carbon; Electrolyzing; Coagulant

\section{Introduction}

Both surface and ground water frequently contains physical, biological, and chemical constituents that can affect the health of those who drink it, lessen its synthetic appeal, and inconvenience the users. It is therefore the duty of the water treatment plant to reduce these constituents to the minimum allowable for consumption, in order to do this a treatment process has to be undertaken. The treatment of surface water, entails passing the raw water through a series of treatment units which are usually the low lift pump, aeration unit, filtration unit and disinfection unit. These are the main processes involved before the water storage and distribution to the community [1].

Synthetic polymers are a product of the second half of this century and polymer science has been applied successfully in water/waste water field to improve the settling process [2]. Many of the suspended particles in raw water (untreated water) are too small to settle out by themselves in a separation by sedimentation process. The benefit of adding polymer is derived from the agglomeration of these individual particles into larger clumps or flocs allowing them to settle and be removed. The list of synthetic polymers which have been successfully applied to treatment of water according to [1] includes high molecular weight polyamines, polyalkaneimines and polyacrylonitriles.

Starches are organic substances which contain carbon, hydrogen and oxygen, which are carbohydrates. They are also known as polysaccharides. Starches are stored in plants such as leaves, bulls, fruits, seeds, tubers and rhizomes of higher plants; they are also present in some lower plants (algae).

According to Whistler R, et al. [3] when the starch granules are intact, they are insoluble in cold water, if the outer membrane has been broken by grinding; the granules swell in cold water and form a gel. When the intact granule is treated with warm water, a soluble portion of the starch diffuses through the granule wall, in hot water the granules swell to such an extent that they burst.

Starch can be completely hydrolysed to glucose by acid, [4] Starch can also be hydrolysed by enzymes into simpler sugars and eventually glucose. The presence of starch can be detected by the addition of iodine.

Polysaccharides like starch are made up of many monosaccharides units joined together [5]. A starch molecule is produced by the combination of many molecules of glucose $\mathrm{C}_{6} \mathrm{H}_{12} \mathrm{O}_{6}$, with the elimination of molecules of water $\mathrm{H}_{2} \mathrm{O}$. Since this splitting out of $\mathrm{H}_{2} \mathrm{O}$ molecules is classed as condensation and many molecules of glucose are involved, starch can be called a condensed polymer of glucose. For the purpose of this thesis, glucose unit will be written as $\mathrm{HOC}_{6} \mathrm{H}_{10} \mathrm{O}_{4} \mathrm{OH}$. Hydroxyl groups from a pair of different glucose molecules eliminate a very large linear molecule in the following way.

$$
\text { Letting } \mathrm{C}_{6} \mathrm{H}_{10} \mathrm{O}_{4}=\mathrm{X}
$$

$$
\text { i.e., }
$$

$\mathrm{HO}-\mathrm{X}-\mathrm{OH}+\mathrm{HO}-\mathrm{X}-\mathrm{OH}+\mathrm{HO}-\mathrm{X}-\mathrm{OH}+-\mathrm{X}-\mathrm{OH} \longrightarrow \mathrm{HO}-\mathrm{X}-\mathrm{O}-\mathrm{X}-\mathrm{O}-\mathrm{X}-\mathrm{O}-\mathrm{X}-\mathrm{OH}+3 \mathrm{H}_{2} \mathrm{O}$ 
Between 200 and 500 glucose molecules can group themselves together in an actual starch molecule, given a possible molecular mass in the region of 60,000 . If the chain molecule formed remains straight, the material is called amylose, but if a branched structure is formed with many off-shoots, the product is amylopectin [6]. Hydrolysis with hot, dilute, tetraoxosulphate (VI) acid, $\mathrm{H}_{2} \mathrm{SO}_{4}$, puts back the $\mathrm{H}_{2} \mathrm{O}$ molecules and breaks up the chain to single glucose molecules again.

Starches can be subdivided into two groups, depending on whether they originate from organs that retain high water content or under conditions were less water is available. Starches have such a multitude of applications that only several of the most prominent can be mentioned here. Whistler R, et al. [3] explains some of the uses of starch. According to them starches from cereals, roots and tubers serve as major food in some countries. In the textile industry, starches and modified starches are employed for sizing yarns preparatory to weaving, for sizing (finishing) cloth and for printing pastes made for starch and dye. Starch is also useful in paper manufacturing [7].

Electrolysis is based on an understanding on the ionic theory. The ionic theory was first presented by Arrhenius in 1887, he postulated that electrolytes in solution are dissociated into electrically charged particles, called ions in such a manner that the total charge on the positive ions equal to the total charge on the negative ions [6]. He further explained that the metallic ions, ammonium ions and hydrogen ions are positively charged while the non-metallic ions and the hydroxide ions are negatively charged. The number of electrical charges carried by an ion is equal to the valency of the corresponding atom or group. Due to the electronic charges carried by these ions, their properties are quite different from those of their corresponding atoms which are electrically neutral.

\section{Description of study area}

Raw water was collected from Opa dam and was used in testing the effectiveness of two prepared solutions, under neutral conditions $(\mathrm{pH} 7)$ and basic condition ( $\mathrm{pH}$ 9). Other samples of water were similarly treated with varying amounts of one percent solution of alum $\left(\mathrm{Al}_{2}\left(\mathrm{SO}_{4}\right)_{3} \cdot 18 \mathrm{H}_{2} \mathrm{O}\right)$.

\section{Materials and Methods}

The method used in preparation of cassava starch was entirely a wet process as described by Davidson J and Summerfelt ST [8]. Tubers of cassava were purchased; these tubers were peeled and washed off the stains. The tubers were then crushed by a mini-mortar and pestle to produce a pulp. The resulting crushed tubers were suspended in water and remained in the water for about three days, this was to soften the tubers, and afterwards the tuber-water mixture was sieved to remove the fibrous materials, leaving what is called the starch milk. The starch milk was allowed to settled for some time (one to two hours) and later the settled starch was separated from water by pouring the top water away. The material left behind was then dried and stored in a desiccator. This material was the starch used in the preparation of the synthetic polymer.

\section{Preparation of synthetic polymer}

$1 \mathrm{~g}$ of the stored starch was mixed with $100 \mathrm{ml}$ of cold distilled water and later $900 \mathrm{ml}$ of hot distilled water $\left(\right.$ about $80^{\circ} \mathrm{C}-100^{\circ} \mathrm{C}$ ) was added to the mixture to make the one litre mark, one millimeter of $1 \mathrm{~N}$ sulphuric acid was then added to the starch solution, this was then electrolyzed for 45 minutes. Figure 1 shows the circuit diagram of the experimental set-up. The dilute sulphuric acid served as electrolyte, aluminium rods were used as electrodes, the rods were pierced longitudinally at the top to allow the passage of copper wires which was used to transmit current either to or from the stabilized power supply unit. The solution was gently stirred throughout the process of charging. The voltage across the electrodes was monitored by a multimeter and was maintained at 40 volts, the current was maintained at about $0.15 \mathrm{amps}$. The solution was charged for 45 minutes.

In the case of sample $\mathrm{A}, 1 \mathrm{~g}$ of activated carbon was added along with the starch before electrolyzing the solution, while in the case of sample B, only starch was used.

Treatment in each case consisted of dosing varying amount of the prepared solutions into the water, the solution and the water were rapidly mixed for 60 seconds and then slowly mixed for 10 minutes using a jar test apparatus. The water was allowed to settle for 30 minutes after which the turbidity of the settled water was measured. Coagulation effectiveness was determined by measuring turbidity of the water samples before and after treatment using a Hachs model 2100 A turbid meters.

\section{Results and Discussions}

In choosing Tetraoxosulphate (VI) acid $\left(\mathrm{H}_{2} \mathrm{SO}_{4}\right)$ as electrolyte, preliminary experiments were performed using Hydrogen Chloride $(\mathrm{HCl})$ as electrolyte. Results obtained from electrolysis experiment are represented in (Table 1). Comparing the two electrolytes it is obvious that $\mathrm{H}_{2} \mathrm{SO}_{4}$ gave better result in turbidity removal. The main disadvantage of using $\mathrm{HCl}$ is that the flocs formed in water did not settle well.

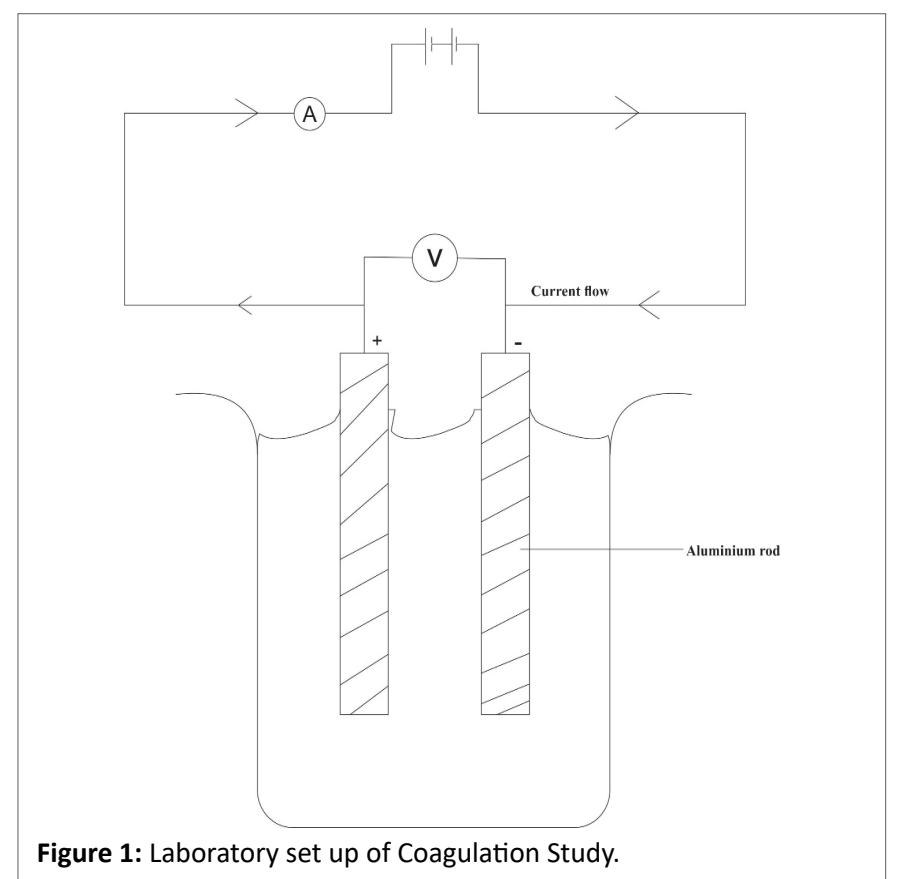

Table 1: Effect of $\mathrm{HCl}$ and $\mathrm{H}_{2} \mathrm{SO}_{4}$ on coagulating characteristics of Sample A.

\begin{tabular}{|c|c|c|}
\hline $\begin{array}{c}\text { Dosage } \\
(\mathbf{m l})\end{array}$ & $\begin{array}{c}\text { Percentage turbidity } \\
\text { removal of sample A } \\
\text { with } \mathbf{~ H C l}(\%)\end{array}$ & $\begin{array}{c}\text { Percentage turbidity } \\
\text { removal of sample A with } \\
\mathbf{H}_{\mathbf{2}} \mathbf{S O}_{\mathbf{4}} \text { (\%) }\end{array}$ \\
\hline 5 & 14.29 & 29.17 \\
\hline 10 & 14.29 & 57.26 \\
\hline 15 & 23.21 & 81.16 \\
\hline 20 & 20.19 & 75.31 \\
\hline 25 & 19.68 & 72.67 \\
\hline
\end{tabular}


When sample A (starch mixed with activated carbon plus dilute $\mathrm{H}_{2} \mathrm{SO}_{4}$ ) and sample $\mathrm{B}$ (starch mixed with water and dilute $\mathrm{H}_{2} \mathrm{SO}_{4}$ ) were prepared for charging, the following observations were made:

I. Some perforations were noticed at the anode and at the cathode bubbles of gas were discharged. The gas was suspected to be hydrogen gas.

II. A white gelatinous substance was noticed at the anode. The substance increased in quantity as charging progressed. This gelatinous substance formed flocs in the solution when stirred.

III. During the charging of Sample A, it was noticed that the activated carbon settled at the bottom of the beaker throughout the charging process, even when stirred, the grains settled again in few seconds. This implies that activated carbon is inert, does not conduct electricity and does not dissolve in water whether cold or hot.

When varying combinations of weight of cassava starch and activated carbon were prepared, charged and tested, the results were as shown in table 2. From the results it can be seen that for effective turbidity removal, the ratio of starch to activated carbon should be 1 . In terms of both effectiveness and economy, $1 \mathrm{~g}$ of starch with $1 \mathrm{~g}$ of activated carbon appears to be the optimum combination to be used in producing a litre solution of Sample A.

\section{Coagulating characteristics of sample A}

The flocs formation at lower dosage of sample A were slow when 2 $\mathrm{ml}, 5 \mathrm{ml}$ and $10 \mathrm{ml}$ of sample A that is $2 \mathrm{~g}, 5 \mathrm{~g}$ and $10 \mathrm{~g}$ of sample A respectively were dosed separately in raw water, it was observed that after the detention time of slow mixing (10 mins), the flocs formed at both neutral and basic medium were small but settled very fast, but some of the flocs were seen floating on the surface of the treated water. However, when higher dosages $15 \mathrm{ml}$ and $20 \mathrm{ml}(15 \mathrm{~g}$ and 20 g) were used, the flocs formed with these dosages also gave a high percentage turbidity removal both in neutral and basic medium (Figures 2 and 3 ). The shapes suggested that there is an optimum concentration of coagulant for maximum turbidity removal beyond which an increase in turbidity results. The results obtained confirmed those findings, suggesting that any dose beyond that needed to effect minimum turbidity decrease might itself contribute to the turbidity of water.

\section{Coagulation characteristics of sample B}

The observed behavior of sample B is almost similar to that of sample A. At low dosage, $5 \mathrm{ml}, 10 \mathrm{ml}$ and $15 \mathrm{ml}(5.05 \mathrm{~g}, 10.10 \mathrm{~g}$ and $15.15 \mathrm{~g}$ respectively) of sample $\mathrm{B}$, the flocs formed both at $\mathrm{pH} 7$ and $\mathrm{pH}$

Table 2: Turbidity removal characteristics of varying combination of cassava starch and activated carbon.

\begin{tabular}{|c|c|c|c|}
\hline $\begin{array}{c}\text { Starch-acti ated carbon } \\
\text { combination S arch (g) Acti ated } \\
\text { Carbon(g) }\end{array}$ & $\begin{array}{c}\text { Volume listed } \\
\text { (ml) }\end{array}$ & $\begin{array}{c}\text { Turbidity removal } \\
\text { (\%) }\end{array}$ \\
\hline 1.0 & 0.5 & 5 & 29.32 \\
\hline & & 10 & 41.62 \\
\hline & & 20 & 70.13 \\
\hline 1.0 & 1.0 & 5 & 28.33 \\
\hline & & 10 & 57.26 \\
\hline & & 20 & 81.60 \\
\hline 0.5 & 1.0 & 5 & 10.69 \\
\hline & & 10 & 27.91 \\
\hline & & 20 & 35.67 \\
\hline
\end{tabular}

9 were small and it took relatively longer time to produce them (Figure 3). The flocs formed at higher dosages; $20 \mathrm{ml}, 25 \mathrm{ml}$ and $30 \mathrm{ml}(20.2$ $\mathrm{g}, 25.25 \mathrm{~g}$ and $30.30 \mathrm{~g}$ respectively) were quite big and as with sample A, settled fast.

\section{Synthetic polymer coagulant versus alum}

Figure 2 shows that the two samples were effective at $\mathrm{pH} 7$, but alum was the most effective giving a maximum percentage turbidity removal of $84.80 \%$ at dosage of $20 \mathrm{~g}$ of sample A in treating $500 \mathrm{ml}$ of raw water and sample B gave the lowest percentage turbidity removal of $64.03 \%$ at a dosage of $20.02 \mathrm{~g}$ of sample B in treating the same volume of raw water. Figure 4 shows that alum has maximum percentage turbidity removal of $90.98 \%$ at a dosage of $3.95 \mathrm{~g}$ of alum solution in treating $500 \mathrm{ml}$ of raw water, giving the most effective in $\mathrm{pH} 9$. Sample A and $B$ have maximum percentage turbidity removal of $89.09 \%$ and $52.78 \%$ respectively at a dosage of $20 \mathrm{~g}$ and $25.55 \mathrm{~g}$ of the samples in treating $500 \mathrm{ml}$ of raw water respectively.

The closeness of percentage turbidity removal of sample A to that of alum can be attributed to the presence of activated carbon in the solution, while sample B low performance in turbidity removal, as compared to sample A and alum, could be attributed to the absence of activated carbon which in the case in sample A served as coagulant aid $[9,10]$.

In figure 2, the effectiveness of activated carbon in sample A shows at a very low dosage, we can then deduct that since sample B shows a

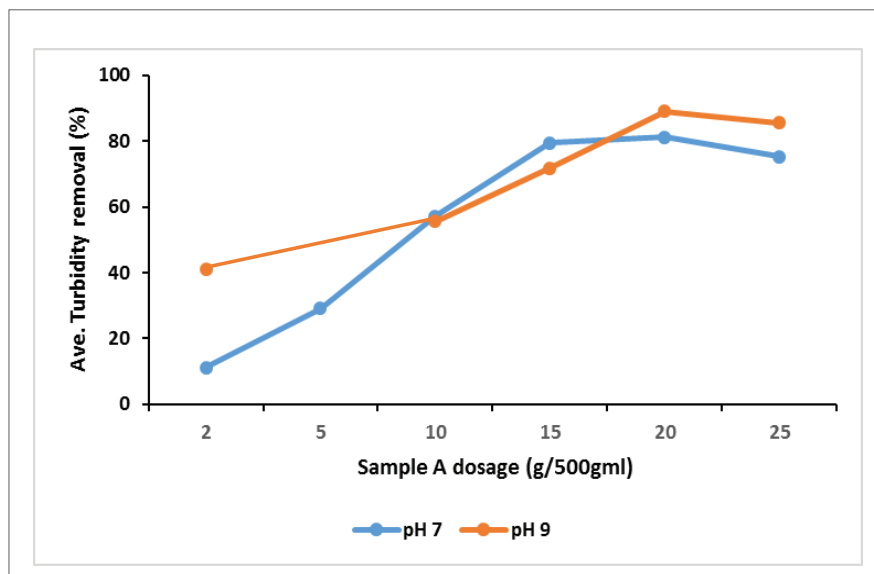

Figure 2: Percentage turbidity removal of sample $\mathrm{A}$ at $\mathrm{pH} 7$ and $\mathrm{pH} 9$.

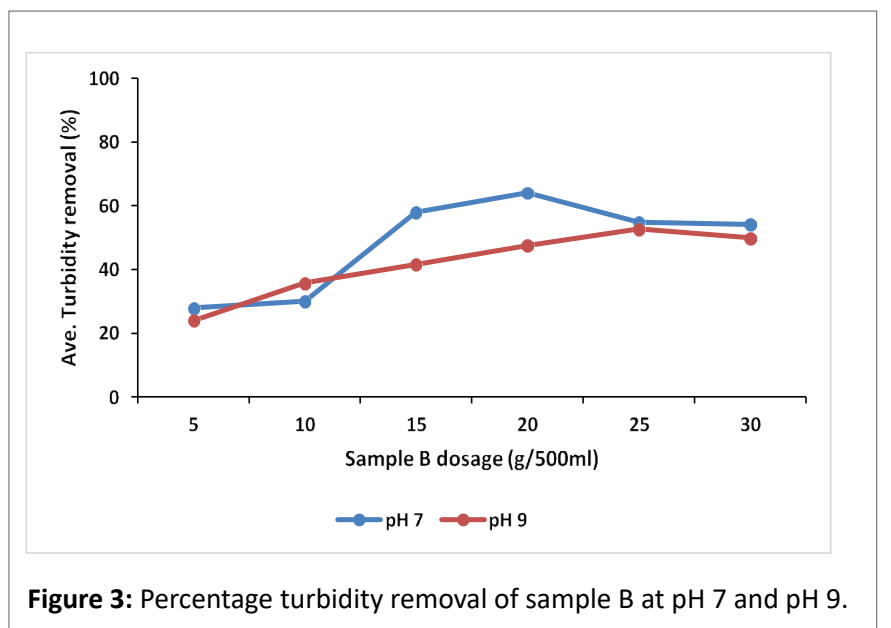




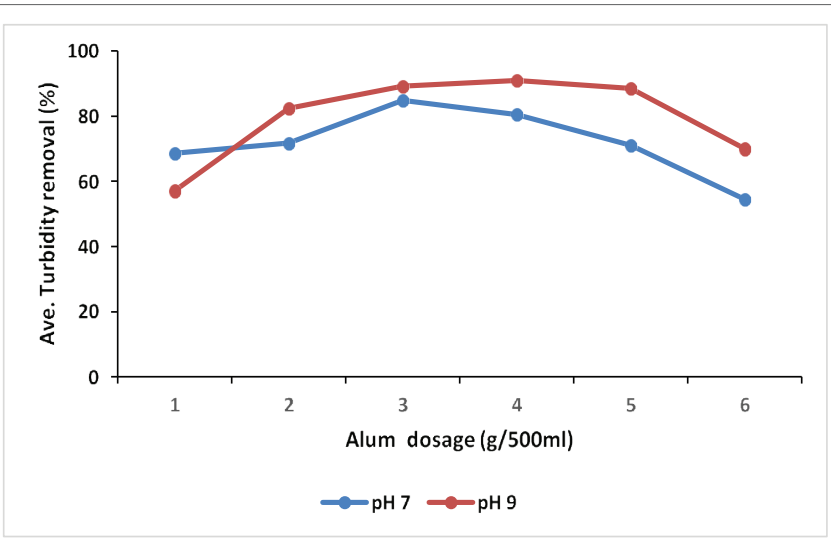

Figure 4: Percentage turbidity removal of alum at $\mathrm{pH} 7$ and $\mathrm{pH} 9$.

decrease in effectiveness in $\mathrm{pH} 9$, then it must be that activated carbon is more effective at $\mathrm{pH} 9$.

\section{Conclusion}

The following conclusion was drawn, based on the results:

1) $1 \mathrm{~g}$ of starch and $1 \mathrm{ml}$ of $1 \mathrm{~N} \mathrm{H}_{2} \mathrm{SO}_{4}$ mixed with distilled water and charged for 45 minutes, ( 0.15 amps, d.c current and 40 volts) gave a product that is effective for water coagulation.

2) Addition of activated carbon, as a coagulant aid, improved the effectiveness of the synthetic polymer coagulant.

3) Synthetic polymer coagulant compared satisfactorily with alum. It gave a maximum turbidity removal of $81.16 \%$ while alum gave a maximum turbidity removal of $84.80 \%$.

4) Both alum and the synthetic polymer were more effective in the basic medium than neutral medium and they both depressed the $\mathrm{pH}$ of the raw water.
5) The solution of the synthetic polymer is stable at room temperature. It still retains its coagulation effectiveness for more than two weeks.

\section{References}

1. Henry AE, Stanley IU, Ogunrinde A, Ogedengbe MO (2005) Preparation of Some Cationic starches as Flocculants for Water. Water Res 16: 1433-1435.

2. Ihekonroye Al, Ngoddy PO (1985) Integrated Food Science and Technology for the Tropics. Macmillan Publishers, London.

3. Whistler R, BeMiller J, Paschall E (2012) Starch Chemistry and Technology. 2nd Edition, Academic Press, New York.

4. Baghvand A, Zand AD, Mehrdadi N, Karbassi A (2010) Optimizing Coagulation Processes for Low and High Turbidity Waters Using Aluminum and Iron Salts. Am J Environ Sci 6: 442-448.

5. Bolto B, Gregory J (2007) Organic polyelectrolytes in water treatment. Water Res 41: 2301-2324.

6. Yu J, Sun DD, Tay JH (2013) Characteristics of coagulation-flocculation of humic acid with effective performance of polymeric flocculant and inorganic coagulant. Water Sci Technol 47: 89-95.

7. Ebeling JM, Sibrell PL, Ogden S, Summerfelt ST (2016) Evaluation of chemical coagulation-flocculation aids for the removal of suspended solids and phosphorus from intensive recirculating aquaculture effluent discharge. Aquac Eng 29: 23-42.

8. Davidson J, Summerfelt ST (2015) Solids removal from a coldwater recirculating system-comparison of a swirl separator and radial-flow settler. Aquac Eng 33: 47-61.

9. Lee CC, Lin SD (2015) Handbook of environmental engineering calculations. 2nd Edition, McGraw Hill Professional, New York, USA.

10. Mark J Hammer Sr, Mark J Hammer Jr (1971) Water and wastewater technology. 6th Edition, Pearson International Edition. 